\title{
Factors Influencing Team Performance: What Can Support Teams in High-Performance Sport Learn from Other Industries? A Systematic Scoping Review
}

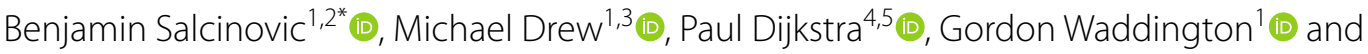 \\ Benjamin G. Serpell ${ }^{1,6,7}$
}

\begin{abstract}
Background: The primary aim of our systematic scoping review was to explore the factors influencing team function and performance across various industries and discuss findings in the context of the high-performance sport support team setting. These outcomes may also be used to inform future research into high-performance teamwork in sport.

Methods: A systematic scoping review of literature published in English since 2000 reporting team-based performance outcomes and included a performance metric that was 'team outcome based' was conducted using search of the Academic Search Ultimate, Medline, Business Source Ultimate, APA PsycInfo, CINAHL, SPORTDiscus, and Military database (ProQuest) using the terms: 'team,' 'function' OR 'dysfunction', 'Perform*'OR'outcome'.

Results: Application of the search strategy identified a total of 11,735 articles for title and abstract review. Seventythree articles were selected for full-text assessment with the aim to extract data for either quantitative or qualitative analysis. Forty-six of the 73 articles met our inclusion criteria; 27 articles were excluded as they did not report a performance metric. Eleven studies explored leadership roles and styles on team performance, three studies associated performance feedback to team performance, and 12 studies explored the relationship between supportive behaviour and performance. Team orientation and adaptability as key figures of team performance outcomes were explored in 20 studies.

Conclusions: Our findings identified 4 key variables that were associated with team function and performance across a variety of industries; (i) leadership styles, (ii) supportive team behaviour, (iii) communication, and (iv) performance feedback. High-performance teams wishing to improve performance should examine these factors within their team and its environment. It is widely acknowledged that the dynamics of team function is important for outcomes in high-performance sport, yet there is little evidence to provide guidance. This inequality between real-world need and the available evidence should be addressed in future research.
\end{abstract}

Keywords: Team effectiveness, Team performance, Leadership, Teamwork, Organisation

\footnotetext{
${ }^{*}$ Correspondence: benjamin.salcinovic@aspetar.com

1 Research Institute for Sport and Exercise, University of Canberra,

Canberra, Australia

Full list of author information is available at the end of the article
} 
'Talent wins games, teamwork wins championships' Michael Jordan.

\section{Key Points}

- Across multiple sectors, four key variables were identified as important for teamwork, team function, team performance and team effectiveness; (i) leadership style (ii) supportive team behaviour (iii) communication, and (iv) performance feedback.

- Evidence obtained in this literature review was unable to illicit causal relationships between the four key variables important for high-performance sport support team function and individual athlete or playing team performance.

- Considering factors associated with teamwork, team function team performance and team effectiveness from other sectors provides leverage points for highperformance sport support teams to improve functions.

\section{Introduction}

Each team has the potential to rise or fall based on the group of people who share the same passion and goals and are working together to achieve success [1]. This narrative is very common in elite sport, an environment that presents considerable health and performance challenges to the athlete and those charged with the responsibility of supporting them [2]. Considering that the success of athlete support teams is often measured by athletic performance outcomes [3], evidence supports the notion that contemporary athlete achievement can be strongly influenced by the function of the athlete support team $[4,5]$. However, given the enormity of the performance and health challenges, elite sport teams may need further inputs beyond traditional structures of coaching staff and limited number of medical personnel to influence health and athletic performance outcomes [6]. Research exploring the dynamics of team function and team performance in an elite sporting environment is one under-appreciated area that can assist meeting this increasing challenge. The nature of team function is a complex phenomenon that is far from resolved [1].

A 'team' can be defined as a group of individuals with specified roles and responsibilities interacting adaptively, interdependently, and dynamically towards a valued common outcome and who are together embedded in an encompassing organisational system, with boundaries and linkages to the broader system context and task environment [7]. Individuals within elite sport support teams include team/athlete coaches and the sports medicine and science team members who are constantly looking for ways to improve the performance and health of the

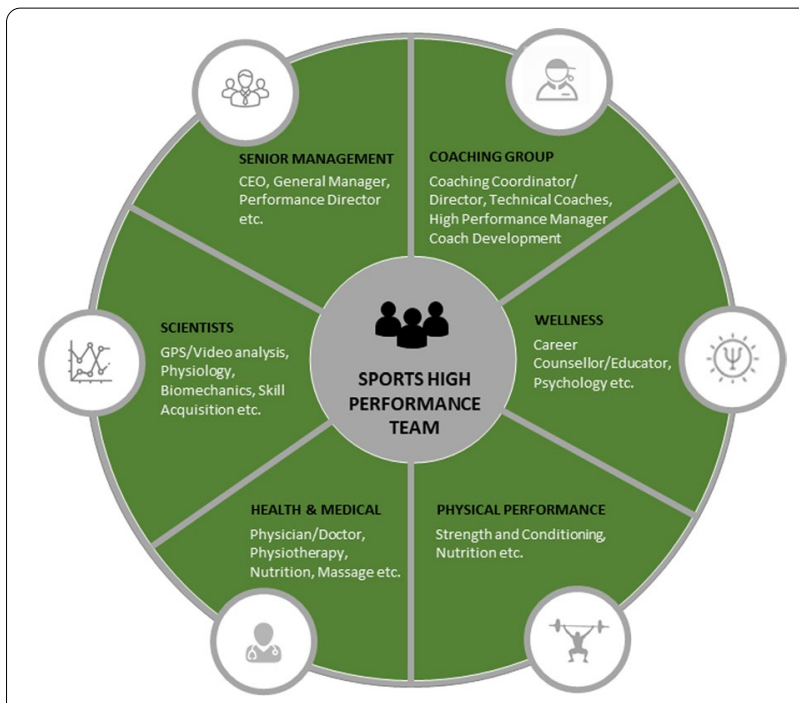

Fig. 1 A model of the support team in high-performance sport

athletes with whom they work [8]. Although varying in definition across sporting contexts, this team of individuals supporting the athlete form the high-performance team (HPT; see Fig. 1) [2, 9-11]. Teamwork refers to the behavioural processes that team members (e.g. members of a HPT) use to achieve work within the team (e.g. communication, collaboration, sharing of expertise), and team function refers to a group of people working towards a common objective. That is, the function of a team relates to the ability to coordinate and cooperatively interact with each other to facilitate task objectives through a shared understanding of the team's resources (e.g., members' knowledge, skills, and experiences), the team's goals and objectives, and the constraints within the work environment [12-14]. Thus, teamwork is a component of team function $[15,16]$. Team performance accounts for the cumulative outputs of the team's actions, sometimes irrespective of how the team may have accomplished the task [7]. The effectiveness of a team, however, takes a holistic perspective in considering not only how the team performed, but also how the team interacted attempting to achieve a desired output (see Additional file 1) [15]. Thus, the performance of support teams in high-performance sport may not be simply reduced to the outcomes of the athletes or teams of athletes they support.

Teams that encourage and facilitate each other's efforts in order to reach a common goal are influenced by issues of leadership [17], supportive team behaviour [18], organisational environment [19] and adaptability [20]. Teams educated about the mechanisms of teamwork (performance monitoring, adaptation, and facilitative leadership) have better performance outcomes [21], 
particularly when team members were able to anticipate each other's behaviours and had better communication mechanisms. The addition of coordinating mechanisms such as supportive team behaviour, team communication and orientation are necessary facilitators of teamwork for a team to be successful [7, 22]. Furthermore, the highperformance sporting environment presents challenges for individuals to function effectively as a team [23]. Despite increased interest in the teamwork construct [24, 25], there are multiple and divergent conceptualisations of teamwork. There is a limited perspective in the present literature regarding the teamwork-team performance relationship [26]. To the authors' knowledge, little work has described what the inputs and processes of teamwork are, nor described methodologies to measure the various influences and determine their role in assessing teamwork relative to performance in high-performance sport.

Challenges within HPTs in the elite sport setting arise because of factors such as organisational climate, professional conflict, power and influence challenges coupled with employment insecurities [19]. Additionally, high risk to reward scenarios, the demand to have a competitive advantage, and the emphasis on winning, have fractured the modern sports culture resulting in disparity and separation of athlete support staff and coaching staff within the same team [2, 27, 28]. Effective team function underpins the achievement of desired outcomes of collaborative work [12]. Consequently, suboptimal teamwork has at times catastrophic results for outcomes of such work [29]. While high-performance teams in elite sport have benefited from considerable scientific advances in physical preparation, participation and recovery practices, elite sport in this instance has not benefited from the science of teamwork effectiveness [30]. The primary aim of our systematic scoping review was to explore the factors influencing team function and performance across various industries and discuss findings in the context of the high-performance sport support team setting. These outcomes may also be used to inform future research into high-performance teamwork in sport.

\section{Methods}

We adopted the Preferred Reporting Items for Systematic Reviews and Meta-analysis extension (PRISMAScR) guidelines [31] to identify a primary set of articles for data extraction and review. The 5-step process as described by Arksey and O'Malley [32] with enhancements as described by Levac et al. [33] was utilised: Identify the research question, identify relevant studies, study selection, chart the data, and collate, summarise, and report the results. In the final step, the review process was supplemented by application of thematic analysis methods [34] to categorise each article within the themes that emerged from relevant literature on team effectiveness models [7, 35-37]. The PRISMA extension for scoping reviews (PRISMA-ScR) checklist was used to ensure complete and transparent reporting [31].

\section{Identification of Relevant Studies}

The article inclusion criteria were; full text, empirical studies published in English, between 2000 and November 2021, and reported objective team-based performance outcomes and included a performance metric that was 'team outcome based', e.g., team effectiveness, cohesiveness, efficiency, reflexivity and potency. We chose to explore only articles with an objective performance based outcome to limit theoretical/speculative content. Articles were excluded under the following criteria: the study had no defined metric of performance outcomes, was a literature review or was an opinion piece.

A search of the Academic Search Ultimate, Medline, Business Source Ultimate, APA PsycInfo, CINAHL, SPORTDiscus, and Military database (ProQuest) was conducted in October 2021 using the terms: 'team', 'function' OR 'dysfunction', 'Perform"' OR 'outcome'. All records retrieved by the search query were imported into Endnote X9 (Thompson Reuters, Carlsbad, CA, USA) and duplicates removed.

\section{Final Study Selection}

Two authors (BS, BGS) independently reviewed titles and abstracts for potential eligibility. For the potentially eligible records, the full-text articles were thereafter retrieved and assessed according to the inclusion and exclusion criteria. The reference lists of the resulting articles were searched by the lead author (BS) for inclusion of additional articles. Any discrepancies were discussed by the reviewers (BS, BGS). No conflicts were identified. The review of full-text articles revealed that those articles that reported a performance metric provided sufficient content data for a continued analysis.

\section{Collating the Results}

Analysis of the methodological and conceptual features of extracted data was thereafter performed by the lead author (BS) to summarise and collate the content of the articles and was subsequently confirmed by a co-author (BGS). Analysis of eligible papers involved describing the type of study which was performed, the occupational domain the study was conducted, where it was conducted, participant characteristics, study aims, performance metric and the category of teamwork. With regards to the conceptual analysis, we focused on examining common and emerging themes among definitions of team performance and their operationalisation (e.g., 
leadership, team orientation) as well as primary research findings as they pertained to team performance. A critical appraisal was not conducted on our findings as the aim of this review is to identify and map the available evidence [32].

The operationalisation categories followed the key themes of teamwork that emerged from the literature on team effectiveness models [7, 12]. Team leadership roles and styles; the ability to direct and coordinate the activities of other team members, assess team performance, assign tasks, develop team knowledge, skills, and abilities, performance goals and feedback; the ability to develop common understandings of the team environment and apply appropriate task strategies to accurately monitor teammate performance, team orientation and adaptability; the ability to adjust strategies based on information gathered from the environment through the use of supportive team behaviour and reallocation of intrateam resources, supportive team behaviour; the ability to anticipate other team members' needs through accurate knowledge about their responsibilities (Fig. 2).

\section{Results}

\section{Literature Search}

The initial literature search identified a total of 11,734 articles for title and abstract review, and one article was retrieved from another source. Seventy-three articles were selected for full-text assessment with the aim to extract data for either quantitative or qualitative analysis. Forty-six of the 73 articles met our inclusion criteria; 27 articles were excluded as they did not report a performance metric. The article selection process is seen in Fig. 3.

\section{Study Characteristics}

The 46 papers identified from the search process were published across a twenty-year period (2000-October 2021) (Figs. 4, 5). Team performance outcomes were examined within business $(n=12)$, sport $(n=8)$, military $(n=6)$, health and social care $(n=3)$, engineering $(n=2)$, education $(n=1)$ or across multiple sectors $(n=14)$ (Fig. 4). In terms of geographical location, the studies were conducted across: North America 61\% (USA, $n=26$; Canada, $n=2$ ), Europe $28 \%$ (UK, $n=4$; Netherlands, $n=3$; Spain, $n=2$; Germany, $n=1$; Italy, $n=1$; Portugal, $n=1$; Europe, unknown $=1$ ), Asia Pacific 9\% (South Korea, $n=1$; Pakistan, $n=1$; India, $n=1$; Australia, $n=1$ ), Africa $2 \%$ (Tunisia, $n=1$ ). There was a positive trend of the number of articles produced over the 2-decade period, 2000-2004 ( $n=7)$,
2005-2009 $(n=10), 2010-2014 \quad(n=12)$ and 2015$2019(n=13)$ (Fig. 5).

Studies utilised mixed methods approaches $(n=17)$ (i.e., questionnaires combined with archival data from financial reports and published articles), cross-sectional surveys $(n=12)$, experimental interventions designed to evaluate team performance among participants $(n=8)$, and interview-based approaches $(n=1)$. Other designs included archival analysis $(n=5)$ and laboratory-based experiments $(n=3)$.

\section{Outcomes \\ Team Leadership Roles and Styles}

Eleven studies explored leadership influences on team performance (Table 1) [38-48]. The role of the team leader is described as pivotal for effective team function, as leaders have responsibility for team members and the direction of all team activity and processes [45, 49]. Leaders who displayed higher cognitive ability, conscientiousness and charisma were better able to mediate their teams to enhance team performance outcomes [40, $41,43,44,46]$. Charismatic and transformational leaders positively change the values and priorities of team members and motivate them to perform beyond their expectations [39, 41]. Leaders within a centralised structure where the decision-making authority is concentrated at the top, and all other lower levels follow the directions coming from the top of the organisation structure, have negative effects on conflict and performance. This leadership model also affects relationships between team members [38, 42, 46]. Our literature search revealed that teams will perform better when team leaders are highly involved in the team's communication and workflow networks [42, 45]. Specifically, in diverse work groups, the nature of interpersonal interactions was found to be an important determinant of group member performance and group effectiveness. For example, referring to gender diversity, one of the studies retrieved argued that a diverse group with low leader-member relationships (i.e. where relationships between team leaders and team members were poor) will not perform highly regardless of how well the leader differentiates role assignments because of insufficient attention to relationships [46]. Leaders act as influential role models, wherein their selfregulatory behaviours directly shape task-related team processes, which was shown to positively influence team performance [44].

\section{Performance Goals and Feedback}

Three studies associated performance monitoring to team performance (Table 2) [50-52]. They explored the use of negative feedback and positive reinforcement as modalities for performance feedback and argued this 


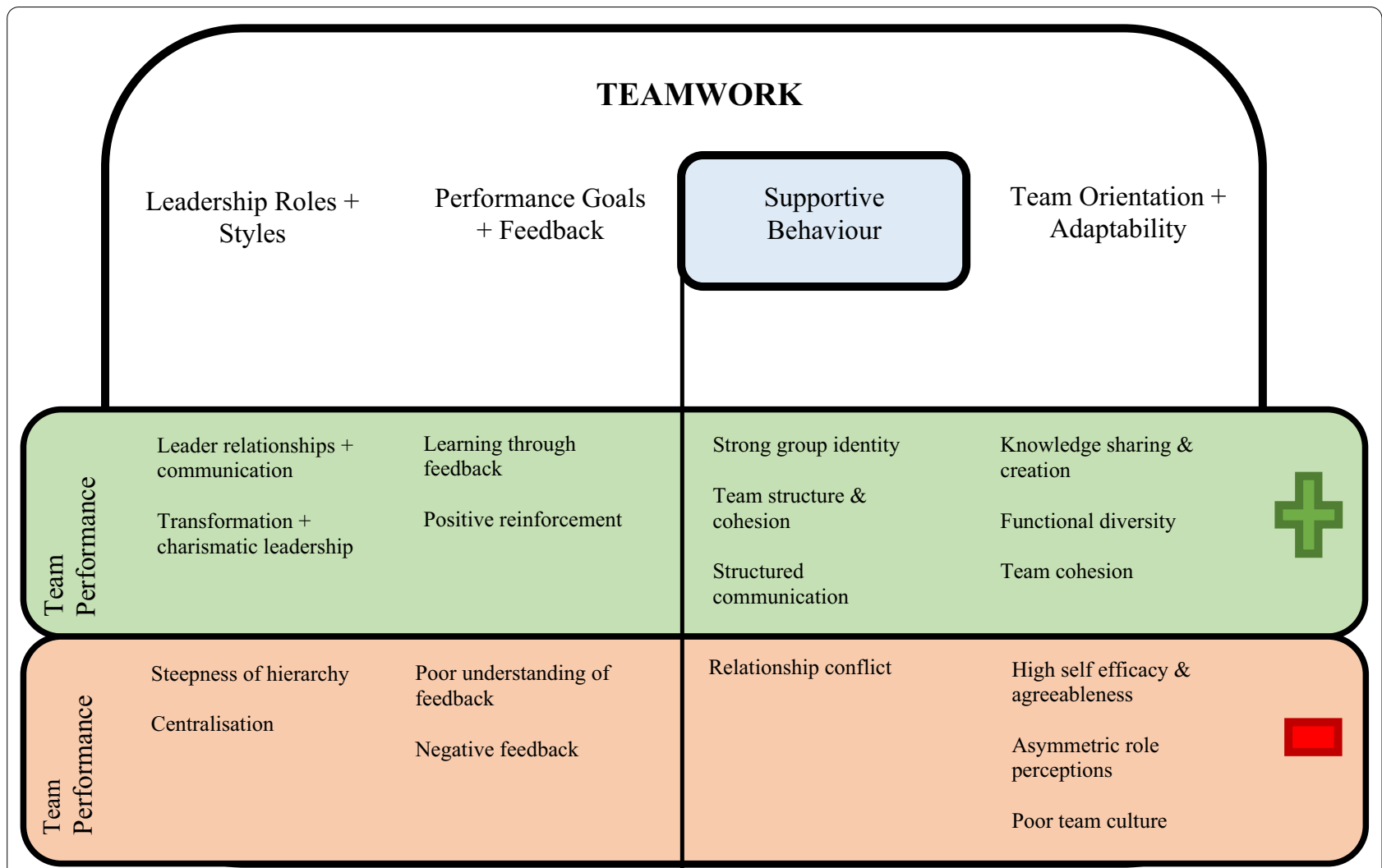

Fig. 2 Concept chart illustrating the characteristics of teamwork and how they are associated with team performance outcomes

can help to build the team, the culture, and the capacity for quality improvement [50-52]. They showed, learning through performance feedback provides team members with the opportunity to learn how to work collaboratively [52], having the potential to (1) shape team culture or attitudes, (2) establish common team goals, and (3) improved understanding of performance standards [51]. However, in one study, it was noted that the effect of team performance feedback on intentions to improve performance was hindered by a poor understanding of how the team could use the feedback and how the feedback was perceived [51].

\section{Supportive Team Behaviour}

Eleven studies [26, 53-62] explored how the relationship between supportive team behaviour, the ability to anticipate other team members' needs through accurate knowledge about their roles and responsibilities [7], and team performance, complement each other (Table 3). Teams with strong group identity, communication and structural cohesion mitigated the adverse consequences of team conflict and collective team failure [53, 56, 60,
61, 63], Relationship conflict within teams has negative consequences on task performance [57, 59]. Task conflict has positive impacts on team performance in teams exhibiting high levels of openness and emotional stability $[54,55,57]$. Members within teams that engage in more cooperative behaviours become more efficient, effective, and viable $[55,56,60,61]$. Supportive team behaviour has additional positive effects on team performance when in combination with performance monitoring [26].

\section{Team Orientation, Organisational Context and Adaptability}

Team orientation, organisational context and adaptability as key features of team performance outcomes were explored in twenty-one studies (Table 4) [38, 63-82]. Team orientation describes how members in teams learn, store, use, and coordinate their knowledge to accomplish team and organisational goals [76]. Team communication and cohesion were found to be key to collaborative work within teams to enhance team performance $[63,68,69,75,80]$. Functional diversity within teams had varying implications for team processes and performance depending on how this 
11734 Records identified through database searching

Military Database (ProQuest) $\mathrm{n}=5,069$

Academic Search Ultimate $\mathrm{n}=2,207$

MEDLINE $\mathrm{n}=2,285$

APA PsycINFO $n=656$

Business Source Ultimate $\mathrm{n}=641$

CINAHL Plus $n=422$

SPORTDiscus $\mathrm{n}=454$

1 Record retrieved through other sources

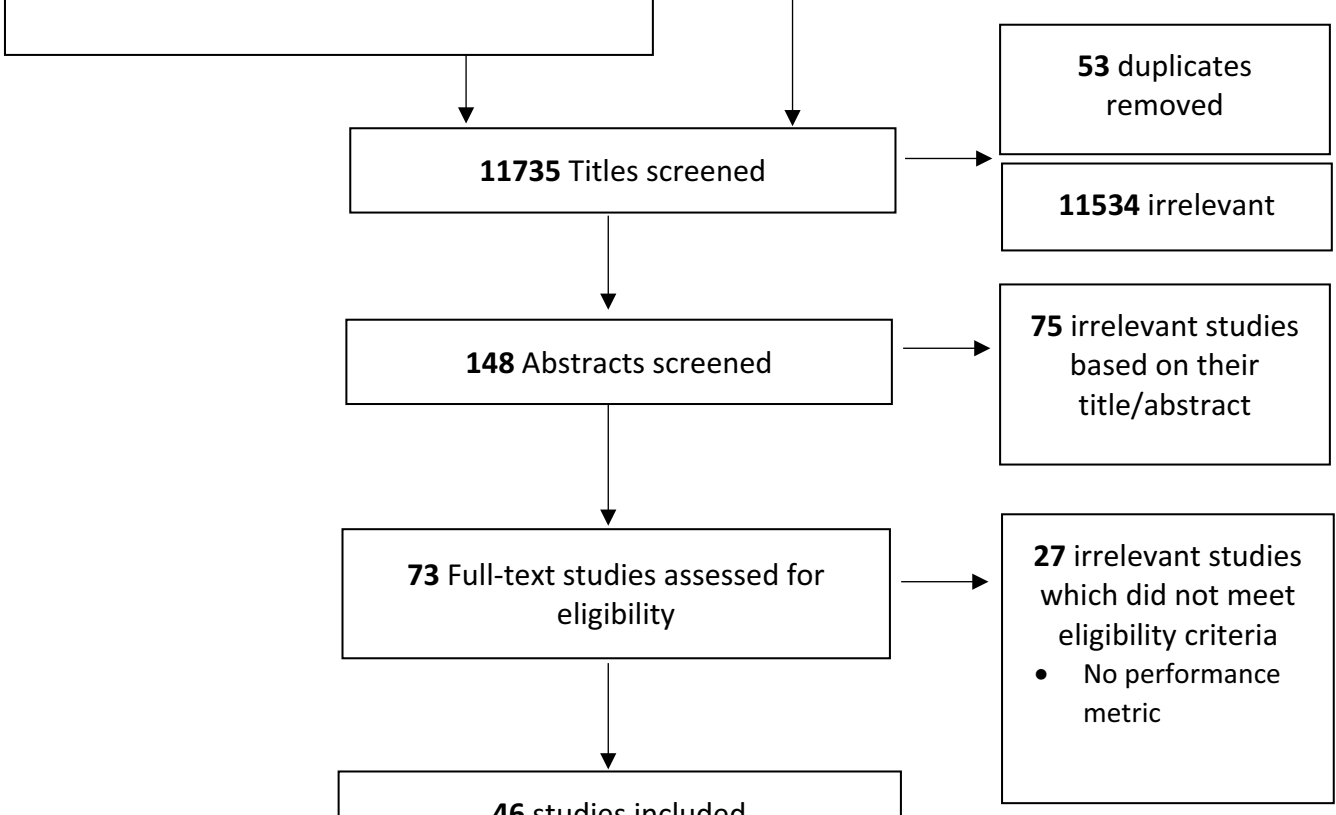

Fig. 3 PRISMA flow chart showing the process for including studies

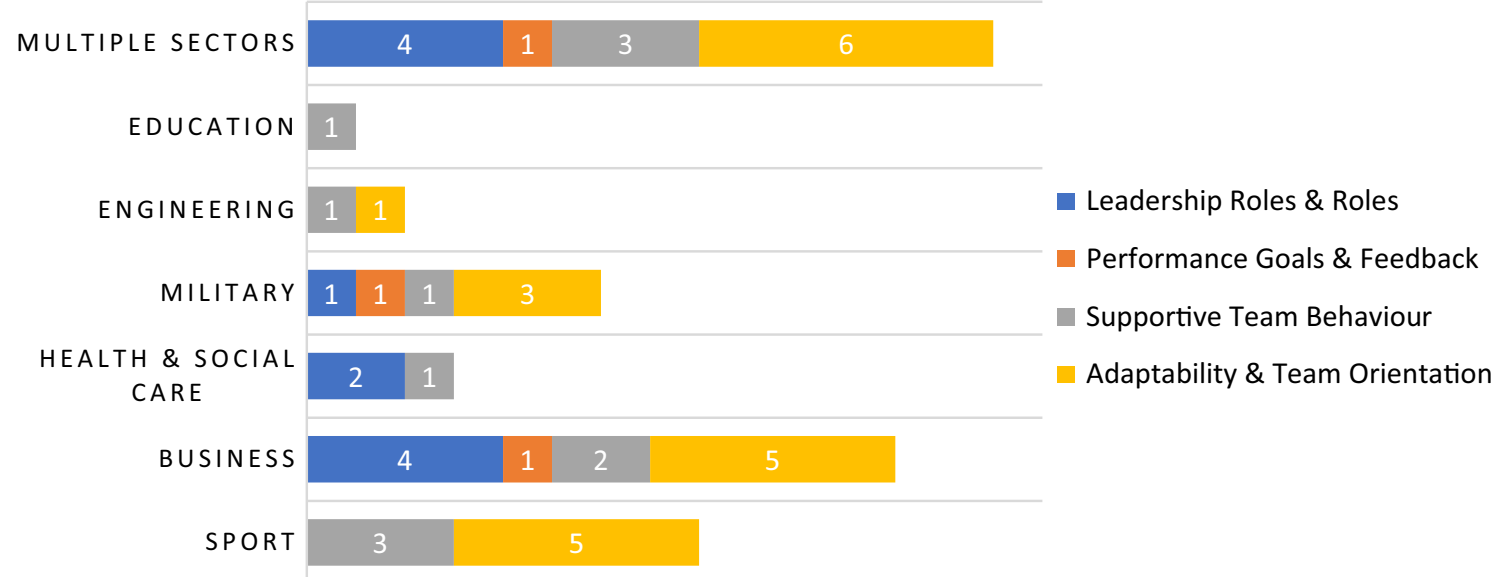

Fig. 4 Trend of the number of articles found between the various workplace domains 


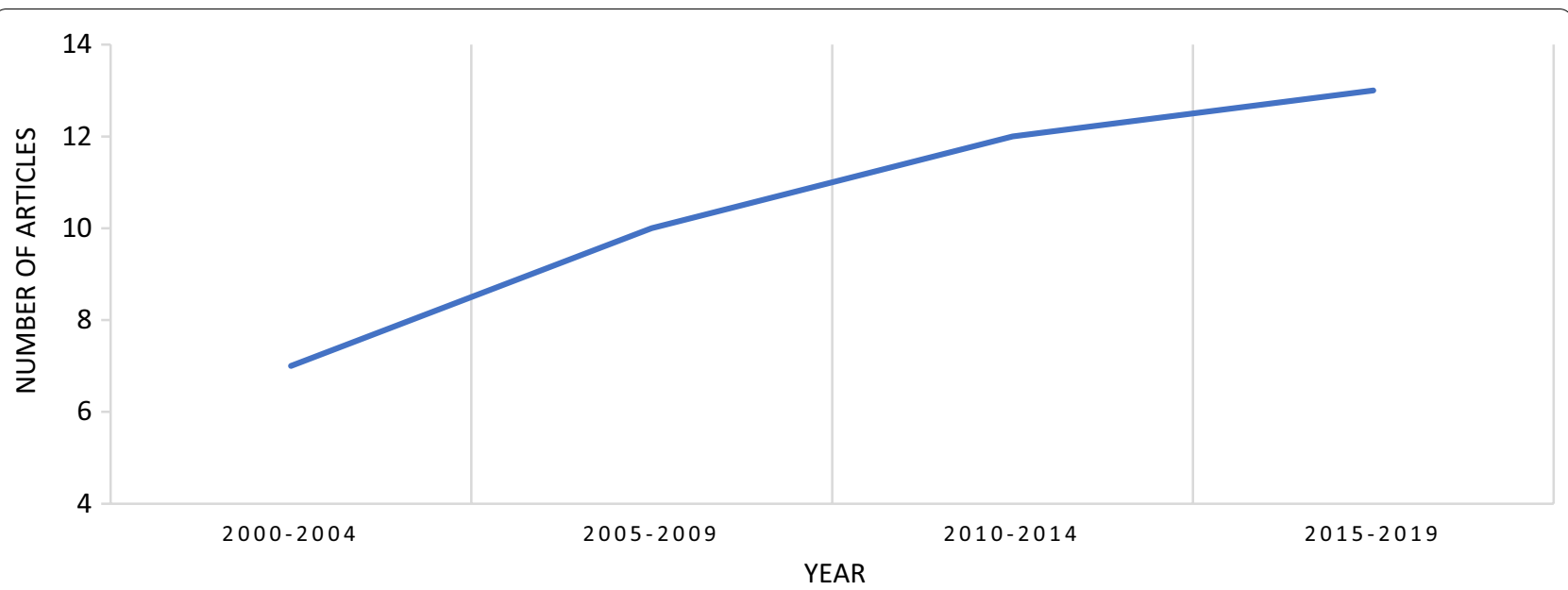

Fig. 5 Trend of the number of articles found over the two-decade period 2000-2020. Note, articles from 2020 to 2021 are not included in this graph so that we can better demonstrate increased article production over time using evenly distributed time brackets

was utilised [83]. Specifically, intrapersonal functional diversity-where each member's experience is distributed over many functional domains (operations, logistics, leadership), rather than focused on one specific functional area-was positively associated with information sharing and collective group performance [68, 83]. The right processes and team culture in an organisation promote team commitment [37]. Organisational context influences team effectiveness, both directly and by determining the initial conditions that promote effective team functioning [84].

A relationship exists between team performance and measures of demographic similarity; described as the team's agreeableness, self-efficacy and creativity $[73,75,83]$, and demographic diversity of age and sex $[65,74]$, In individuals low on self-efficacy and agreeableness, team climates encouraging exploitation and exploration respectively deliver increasing performance and creative benefits. When team encouragement for exploitation-treating someone unfairly in order to benefit from their work-increases, the returns on such encouragement diminish, and individuals with high levels of self-efficacy and agreeableness show less additional performance and creative returns [72, 73]. Age, job tenure and performance dissimilarity are also associated with lower team performance as broader contextual factors in the social world are potential obstacles to effective team functioning $[65,74]$.

\section{Discussion}

This systematic scoping review identified four key variables that were associated with team function and performance across a variety of industries; (i) leadership styles [17], (ii) supportive team behaviour [18], (iii) communication, and (iv) performance feedback [20]. High-performance teams may wish to consider prioritising these variables to improve health and performance outcomes. However, this should be done with caution given limited evidence was identified in sport relative to these factors. Team function and performance in the context of support teams in high-performance sport may be better enhanced if we first work towards understanding the behaviour of those four key variables relative to each other in the broader sports team [85].

\section{Leadership Styles Influence Team Cohesion and Performance}

In sport, leadership behaviour is not just important for individual players; it is important for the team as a whole as it establishes an interpersonal environment characterised by support, respect, trust and appreciation of staff and players [86], which ultimately have a positive influence on team cohesion and performance [86]. Leadership styles that promote back up behaviour were suggested to enhance team cohesion. Highly cohesive teams worked together more efficiently and, consequently, performed better than less cohesive teams [39]. It is well established that leadership serves as a critical input for influencing group processes and output, and that leaders can shape team members' attitudes, beliefs, and values [44]. Sports psychology research supports the view that leadership behaviours are associated with higher levels of motivation and performance [87-89], increased well-being [90], and increased task/team cohesion [87]. A study of leadership styles of football coaches indicated that leadership behaviours that communicated a clear and positive vision of the future appeared to reduce the risk of severe 
Salcinovic et al. Sports Medicine - Open

(2022) 8:25

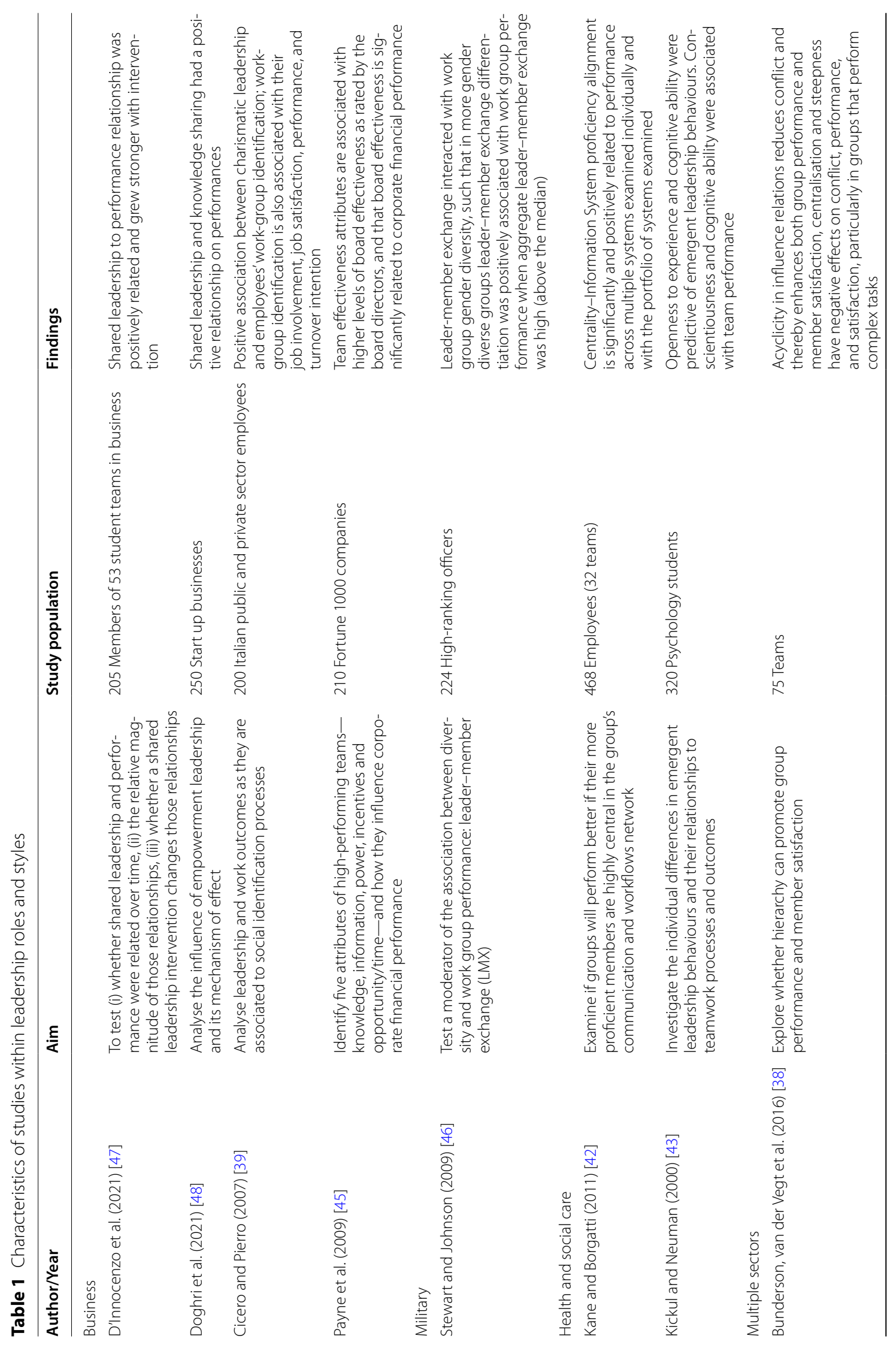

Page 8 of 18 


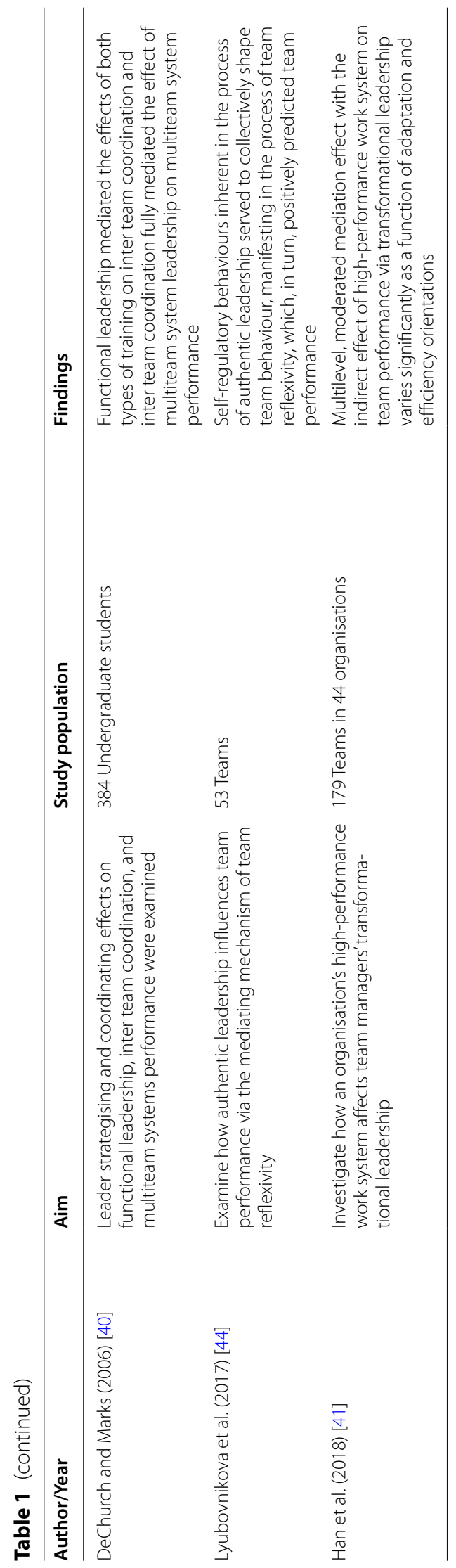




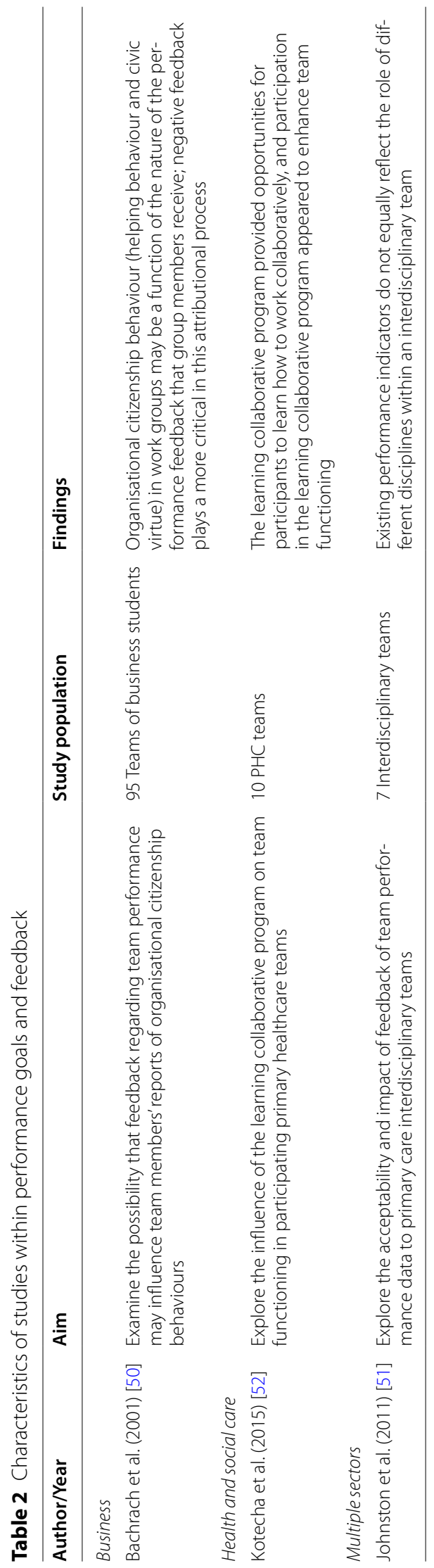




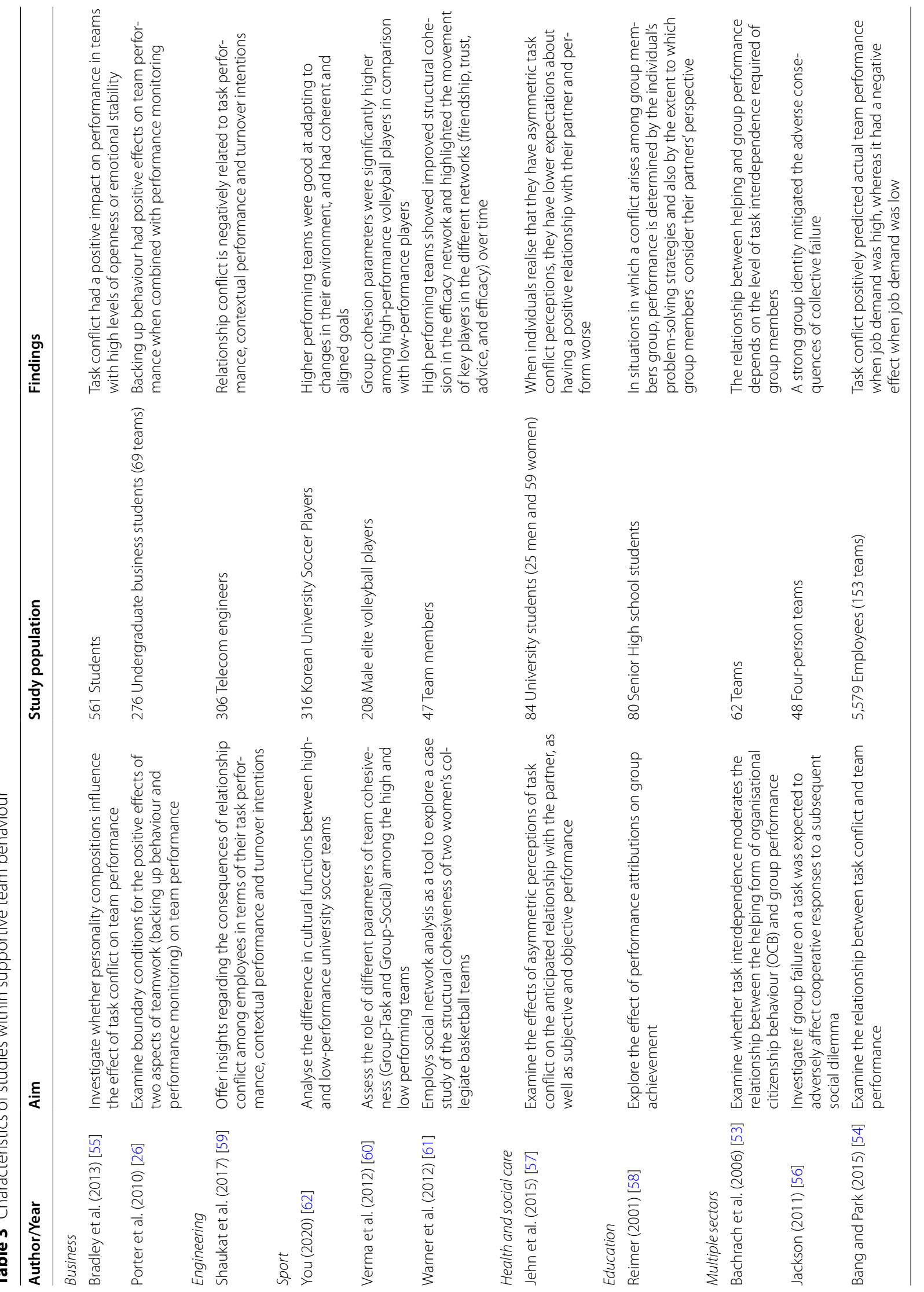


injuries by $29 \%-40 \%$ [86]. This is in line with the idea that transformational leaders develop an image of the future of their organisation and communicate that vision to their subordinates. In contrast, leadership that does not promote supporting behaviour and adaptability might risk insufficient collaboration within the team, poor decision-making and high stress. This is likely to lead to the team underperforming [11].

Our findings demonstrate that charismatic leadership has positive effects on team performance [39]. This is contrary to the evidence supporting this style of leadership within the sport setting. In a recent study in the sport of football [86], no correlation was found between charismatic leadership and injury rates or players' availability. It is incumbent on the leader to establish positive rapport across the team as this is an important determinant of team performance and effectiveness [46].

\section{Team Communication and Feedback Influence How a Team May Function}

Open communication and feedback about both strengths and weaknesses were identified as a characteristic of well-performing teams, and poor communication was a marker of dysfunctional relationships [91]. When teams of multidisciplinary practitioners adopt this teamwork approach, they have been described as an 'interdisciplinary team', differentiated by their integration of knowledge and collaborative behaviours beyond that seen in 'multidisciplinary teams', where individuals work towards their own goals with limited interaction [84, 92]. This may be explained by the mechanism through which teams collectively encode, store, and retrieve knowledge; described as transactive memory systems (TMS). TMS facilitates team shared knowledge and communication by developing a structure and organisation $[64,67,69,77$, 79-81], and supporting the development, integration and change of knowledge and its content [79].

Communication is considered an important mediator of performance in team sports [93]. This notion is supported by work which highlights the importance of distributed decision-making in groups of people [94], and in fact, a recent study in the sport of football concluded that the quality of communication within a team was associated with both injury rates and player availability [91]. Teams with high internal communication quality had lower injury rates and higher player availability than teams with low communication quality [91]. Low communication quality between the head coach and the medical team was significantly associated with the injury rate; such teams had a 6\%-7\% lower player availability at training and matches and a 50\% higher injury burden, compared with teams with moderate or high communication quality [91]. High quality communication between individuals in different roles is likely to promote good collaborations and facilitate the benefits derived from multiple perspectives in informed decisions, for instance, return to play decision or major decisions regarding the well-being of players [2, 91].

Low-quality communication is likely to increase the risk of misunderstandings and promote one-sided decision-making and high stress, which in the long run might contribute to the risk of injuries [11,91]. Without effective communication and feedback, it is difficult to modify individual training plans (e.g. training load and other environment considerations like training surface) according to athlete age, position and medical history. Good communication, management and training restrictions can assist players to continue playing and performing throughout the season without exacerbating the injury [91]. The tendency to weight negative information more heavily than positive information during feedback processes could help account for the asymmetrical effects that negative (as opposed to positive) feedback has on group members' implicit performance [50]. Feedback strongly influences emotional reactions, which in turn affect employees' attitudes and role behaviours. Therefore, leaders may be better off framing their feedback to subordinates in a positive rather than a negative manner as this comes with increased employee commitment and organisational citizenship behaviour [95]. Considering teamwork factors that have been demonstrated to shape outcomes of teamwork in organisations outside of sport provides leverage points for teams to improve team function [25].

\section{Team Culture May Mitigate Against Consequences of Team Conflict}

Team culture-a shared set of values that inform a group's behaviour-is considered one of the most prominent contributors to the success of a sporting organisation $[96,97]$. Teams with strong team culture mitigate the adverse consequences of team conflict and collective team failure $[53,56,60,61,63]$ as it facilitates supportive behaviour and accountability by having clear purpose, well-defined roles and organisational policies [10, 98]. In the sport setting, there are established hierarchies based around teamwork [2]. The organisational culture and climate of elite sport have been described as 'rife' with culturally-driven challenges that include interdepartmental communication problems, coach-athlete conflict, interference from owners, negative reporting in the media and staff being required to continually justify how their input impacts performance [23]. Sports teams that foster acceptance of group goals, promote communication and positive conflict had a positive relationship with team cohesion [99]. Teams who are able to address conflict 


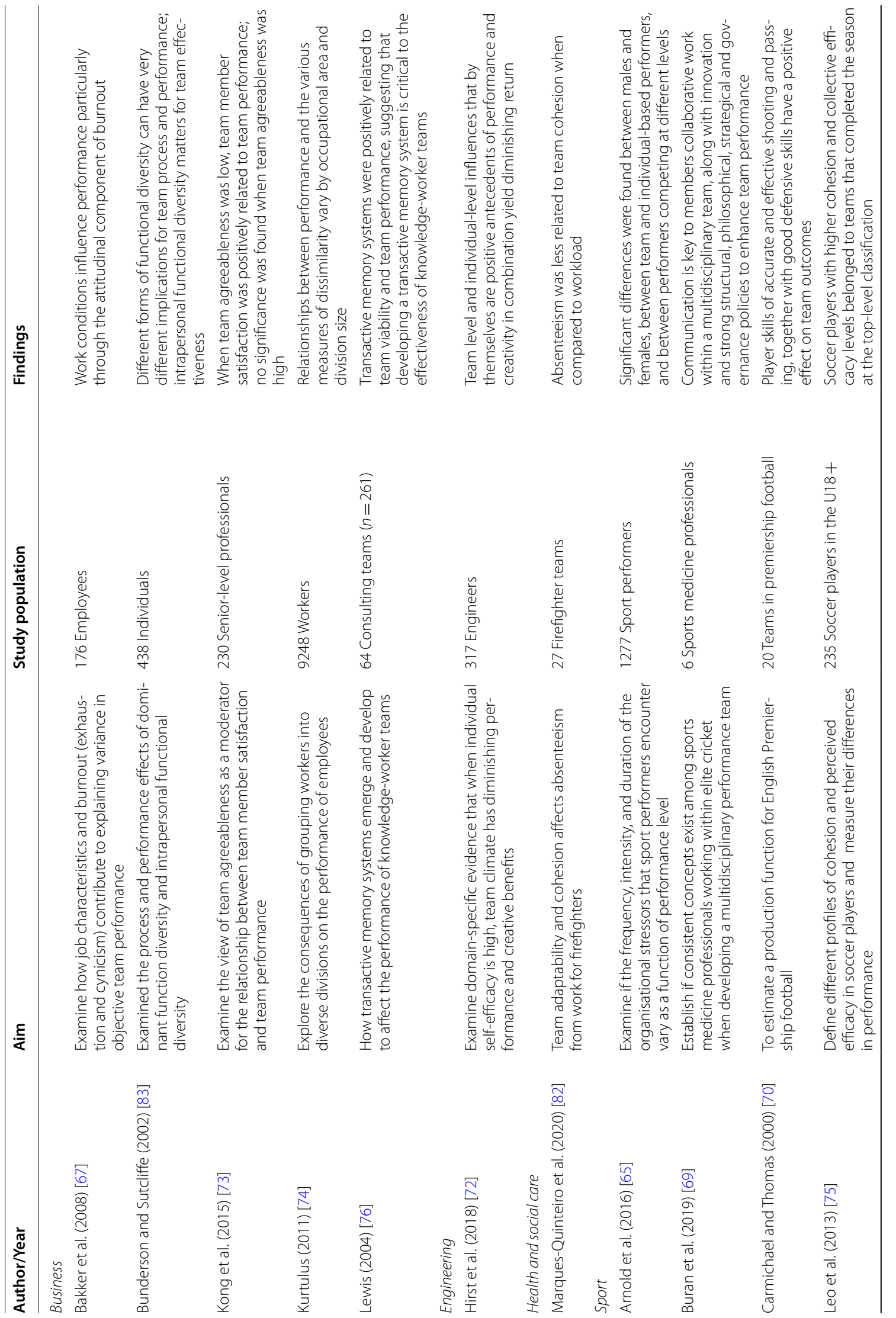




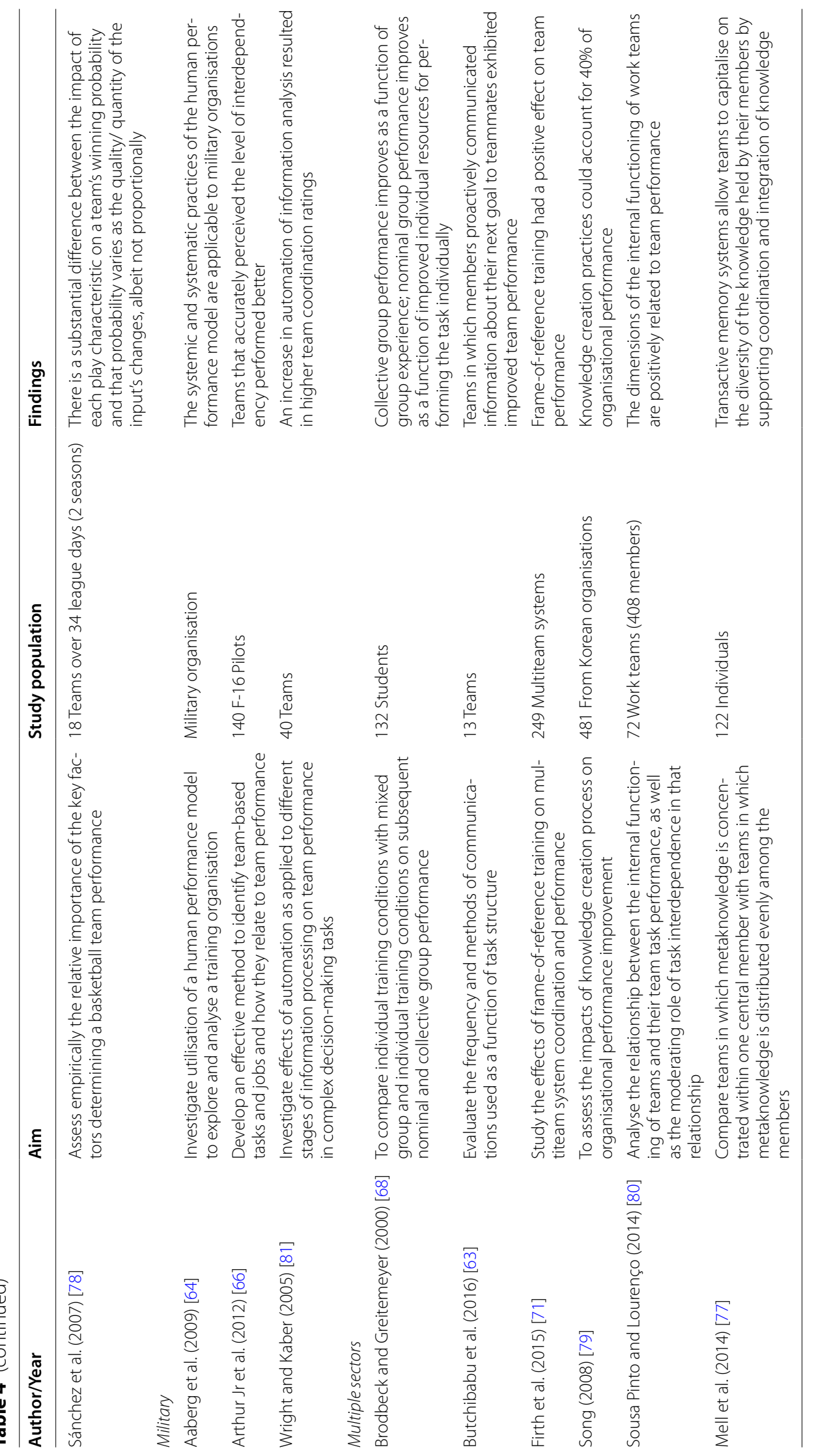


directly are better able to develop an open constructive atmosphere and forge a stronger team identity [100]. However, HPT may exhibit high levels of team conflict, particularly within high pressure environments like that in elite sport [23] which can interfere with effective team performance [101]. When team members' perceptions of their individual role within the team are in alignment with how other team members perceive their roles, HPT can avoid high levels of team conflict and exhibit better team performance [101].

\section{Bias, Limitations and Future Research}

Within our systematic scoping review, we identified commonly interchangeable use of terminology which makes pooling and summarising the results across industries and domains difficult. The studies identified displayed a publication bias towards cross-sectional studies. Such study designs are unable to assess the dynamic nature of working in teams. Teams are complex, dynamic systems that 'adapt' to new knowledge, relationships, external events and environment constraints among many other potential inputs. It is therefore important to carefully consider optimal study designs when examining team behaviours and their consequences [7] through certain study designs. Future research to agree on a taxonomy of definitions will enable research in this area to be applied to a sporting context and compared across investigations. An expected limitation of this review was the lack of existing research that satisfied the search criteria for data extraction. To minimise this limitation, we searched a common array of academic research databases leading to a sensitive search strategy which identified many false positives based on the inclusion criteria. No studies identified in this systematic scoping review investigated causal relationships. Future research investigating whether certain inputs or process improve team function may benefit from utilising causal inference methodology.

We concede this review has explored the effect of support team-teamwork/team effectiveness/team function on injury incidence and availability of athletes; however, its effect on athlete or playing team sporting performance has not been commensurately discussed. To the knowledge of the researchers, no evidence linking support team-team work to individual or playing team sporting performance exists. If we are to consider, however, increased athlete availability increases training opportunity, and that the people in the broader team environment can affect competition performance in athletes [102-104], it is reasonable to assume support team-teamwork/team effectiveness/team function affects athlete or playing team sporting performance similarly to how it affects athlete injury incidence and availability.

\section{Conclusion}

Across various sectors, we identified that improved team function and performance are associated with leadership, supportive team behaviour, communication, and performance feedback. In the context of complex sporting organisations where leaders must respond to multiple stakeholders and meet performance goals across multiple dimensions of effectiveness, addressing the reported challenges and considering the importance of organisational commitment to team development can help ensure that team objectives are effectively designed, delivered, and sustained. While the evidence obtained in this literature review was unable to elicit causal relationships between these factors and enhanced sport performance, it provides a point at which high-performance sport support teams can commence their investigation and interventions to improve team function and performance. This review will pave the way for future research; however, no agreement currently exists on terminology and definitions for performance outcomes to support performance analyses of teamwork and to establish if a performance support team that works effectively will enable better health and performance outcomes for their athletes/sport team. It is widely acknowledged that the dynamics of team function is important for outcomes in high-performance sport, yet there is a dearth of evidence to provide guidance in the high-performance sport context; hence, we have explored team work in alternate sectors. This inequality between real-world need and the available evidence should shape future research to work towards examining team effectiveness related to achieving both health and performance outcomes in elite sport.

\section{Abbreviations}

HPT: High-performance team; TMS: Transactive memory systems.

\section{Supplementary Information}

The online version contains supplementary material available at https://doi. org/10.1186/s40798-021-00406-7.

Additional file 1. Notes.

\section{Acknowledgements}

Not applicable.

\section{Authors' contributions}

BS and BGS conceived and designed the analysis. BS and BGS conducted the systematic literature search. BS, BGS, MD, PD and GW gave final approval for the eligibility of all articles included in the analysis and provided critical revision of the article. BS wrote the first draft of the manuscript and was responsible for the integrity of the data analysis. All authors read and approved the final manuscript.

Funding

This review was not supported by any research funding. 


\section{Availability of data and materials}

All relevant data are included within this article.

\section{Declarations}

\section{Ethics approval and consent to participate}

Formal consent is not required for this type of study.

\section{Consent for publication}

Not Applicable.

\section{Competing interests}

The authors declare that they have no competing interests.

\section{Author details}

${ }^{1}$ Research Institute for Sport and Exercise, University of Canberra, Canberra, Australia. ${ }^{2}$ Rehabilitation Department, Aspetar Orthopedic and Sports Medicine Hospital, Doha, Qatar. ${ }^{3}$ Athlete Availability, Applied Technology and Innovation, Australian Institute of Sport, Bruce, Australia. ${ }^{4}$ Department of Medical Education, Aspetar Orthopedic and Sports Medicine Hospital, Doha, Qatar. ${ }^{5}$ Department for Continuing Education, University of Oxford, Oxford, UK. ${ }^{6}$ School of Science and Technology, University of New England, Armidale, NSW, Australia. ${ }^{7}$ Geelong Cats Football Club, Geelong, VIC, Australia.

Received: 20 June 2021 Accepted: 29 December 2021

Published online: 22 February 2022

\section{References}

1. McEwan D, Beauchamp MR. Teamwork in sport: a theoretical and integrative review. Int Rev Sport Exerc Psychol. 2014;7(1):229-50.

2. Dijkstra HP, Pollock N, Chakraverty R, Alonso JM. Managing the health of the elite athlete: a new integrated performance health management and coaching model. Br J Sports Med. 2014;48(7):523-31.

3. Cruickshank A, Collins D. Change management: the case of the elite sport performance team. J Chang Manag. 2012;12(2):209-29.

4. Guzmán I. Measuring efficiency and sustainable growth in Spanish football teams. Eur Sport Manag Q. 2006;6(3):267-87.

5. Smith ACT, Stewart B. The special features of sport: a critical revisit. Sport Manag Rev. 2010;13(1):1-13.

6. Drust B, Green M. Science and football: evaluating the influence of science on performance. J Sports Sci. 2013;31:1377-82.

7. Salas E, Sims DE, Burke CS. Is there a "big five" in teamwork? Small Group Res. 2005;36(5):555-99.

8. Odetoyinbo K. Performance health management in English professional football a mixed method study. Bath: University of Bath; 2019.

9. Gabbett TJ, Kearney S, Bisson LJ, Collins J, Sikka R, Winder N, et al. Seven tips for developing and maintaining a high performance sports medicine team. Br J Sports Med. 2018;52(10):626-7.

10. Hankemeier D, Manspeaker SA. Perceptions of interprofessional and collaborative practice in collegiate athletic trainers. J Athl Train. 2018:53(7):703-8.

11. Mooney M, Charlton PC, Soltanzadeh S, Drew MK. Who 'owns' the injury or illness? Who 'owns' performance? Applying systems thinking to integrate health and performance in elite sport. Br J Sports Med. 2017;51(14):1054-5.

12. Kozlowski SW, Ilgen DR. Enhancing the effectiveness of work groups and teams. Psychol Sci Public Interest. 2006;7(3):77-124.

13. Morgan BB Jr, Glickman AS, Woodard EA, Blaiwes AS, Salas E. Measurement of team behaviors in a Navy environment. Research Triangle Park, NC: Battelle Columbus Labs; 1986.

14. Salas E, Sims DE, Klein C. Cooperation at work. In: Spielberger C, editor. Encyclopedia of applied psychology, vol. 1. Cambridge: Academic Press; 2004. p. 497-505.

15. Kozlowski SW, Bell BS. Work groups and teams in organizations. In: Weiner I, Schmitt NW, Highhouse S, editors. Handbook of psychology, vol. 12. 2nd ed. Hoboken: Wiley; 2012

16. Searle JR. Collective intentions and actions. Intent Commun. 1990;195:220.
17. Zaccaro SJ, Rittman AL, Marks MA. Team leadership. Leadersh Q. 2001;12(4):451-83.

18. Porter CO. Goal orientation: effects on backing up behavior, performance, efficacy, and commitment in teams. J Appl Psychol. 2005:90(4):811.

19. Malcolm D, Scott A. Professional relations in sport healthcare: workplace responses to organisational change. Soc Sci Med. 2011;72(4):513-20.

20. Kozlowski S, Gully S, Nason E, Smith E. The changing nature of work performance: implications for staffing, personnel actions, and development. SIOP Frontiers Series. San Francisco: Jossey-Bass; 1999. p. 240-92.

21. Entin EE, Serfaty D. Adaptive team coordination. Hum Factors. 1999:41(2):312-25.

22. Shiflett $S$. Toward a general model of small group productivity. Psychol Bull. 1979:86(1):67.

23. Eubank M, Nesti M, Cruickshank A. Understanding high performance sport environments: impact for the professional training and supervision of sport psychologists. Sport Exerc Psychol Rev. 2014;10(2):30-6.

24. McEwan D, Ruissen GR, Eys MA, Zumbo BD, Beauchamp MR. The effectiveness of teamwork training on teamwork behaviors and team performance: a systematic review and meta-analysis of controlled interventions. PLOS ONE. 2017;12(1):e0169604-e.

25. Schmutz JB, Meier LL, Manser T. How effective is teamwork really? The relationship between teamwork and performance in healthcare teams: a systematic review and meta-analysis. BMJ Open. 2019;9(9):e028280.

26. Porter $\mathrm{COLH}$, Gogus $\mathrm{Cl}$, Yu RC-F. When does teamwork translate into improved team performance? A resource allocation perspective. Small Group Res. 2010:41(2):221-48.

27. Ashton $\mathrm{H}$. Are we sports physiotherapists working as a team as well as we could? Br J Sports Med. 2016;50(5):257.

28. Gilmore S, Wagstaff C, Smith J. Sports psychology in the English premier league: 'it feels precarious and is precarious.' Work Employ Soc. 2018;32(2):426-35.

29. Rosen MA, DiazGranados D, Dietz AS, Benishek LE, Thompson D, Pronovost PJ, et al. Teamwork in healthcare: key discoveries enabling safer, high-quality care. Am Psychol. 2018;73(4):433-50.

30. Chamberlain P. The science of winning [Sports Technology]. Eng Technol. 2008;3(14):16-9.

31. McGowan J, Straus S, Moher D, Langlois EV, O'Brien KK, Horsley T, et al. Reporting scoping reviews-PRISMA ScR extension. J Clin Epidemiol. 2020;123:177-9.

32. Arksey H, O'Malley L. Scoping studies: towards a methodological framework. Int J Soc Res Methodol. 2005;8(1):19-32.

33. Levac D, Colquhoun H, O'Brien KK. Scoping studies: advancing the methodology. Implement Sci. 2010;5(1):69.

34. Braun V, Clarke V. Using thematic analysis in psychology. Qual Res Psychol. 2006;3(2):77-101

35. Cohen SG, Bailey DE. What makes teams work: group effectiveness research from the shop floor to the executive suite. J Manag. 1997:23(3):239-90

36. Katzenbach JR, Smith DK. The discipline of teams. Boston: Harvard Business Press; 2008.

37. Larson CE, Larson C, LaFasto FM. Teamwork: what must go right/what can go wrong. New York: SAGE; 1989.

38. Bunderson JS, van der Vegt GS, Cantimur Y, Rink F. Different views of hierarchy and why they matter: hierarchy as inequality or as cascading influence. Acad Manag J. 2016;59(4):1265-89.

39. Cicero L, Pierro A. Charismatic leadership and organizational outcomes: the mediating role of employees' work-group identification. Int J Psychol. 2007:42(5):297-306.

40. DeChurch LA, Marks MA. Leadership in multiteam systems. J Appl Psychol. 2006;91(2):311-29.

41. Han JH, Liao H, Taylor MS, Kim S. Effects of high-performance work systems on transformational leadership and team performance: investigating the moderating roles of organizational orientations. Hum Resour Manage. 2018;57(5):1065-82.

42. Kane GC, Borgatti SP. Centrality-is proficiency alignment and workgroup performance. MIS Q. 2011;35(4):1063-78.

43. Kickul J, Neuman G. Emergent leadership behaviors: The function of personality and cognitive ability in determining teamwork performance and KSAS. J Bus Psychol. 2000;15(1):27-51. 
44. Lyubovnikova J, Legood A, Turner N, Mamakouka A. How authentic leadership influences team performance: the mediating role of team reflexivity. J Bus Ethics. 2017;141(1):59-70.

45. Payne GT, Benson GS, Finegold DL. Corporate board attributes, team effectiveness and financial performance. J Manag Stud. 2009;46(4):704-31.

46. Stewart MM, Johnson OE. Leader-member exchange as a moderator of the relationship between work group diversity and team performance. Group Org Manag. 2009;34(5):507-35.

47. D'Innocenzo L, Kukenberger M, Farro A, Griffith J. Shared leadership performance relationship trajectories as a function of team interventions and members' collective personalities. Leadersh Q. 2021:32:101499.

48. Doghri S, Horchani S, Ben-Mraber S. Leadership style effect on team performance: the mediating role of knowledge sharing. Change Manag: Int J. 2021;21(1):29-55.

49. Mountjoy M, Sundgot-Borgen J, Burke L, Ackerman KE, Blauwet C, Constantini N, et al. International Olympic Committee (IOC) consensus statement on relative energy deficiency in sport (RED-S): 2018 update. Int J Sport Nutr Exerc Metab. 2018;28(4):316-31.

50. Bachrach DG, Bendoly E, Podsakoff PM. Attributions of the "causes" of group performance as an alternative explanation of the relationship between organizational citizenship behavior and organizational performance. J Appl Psychol. 2001;86(6):1285-93.

51. Johnston S, Green M, Thille P, Savage C, Roberts L, Russell G, et al. Performance feedback: an exploratory study to examine the acceptability and impact for interdisciplinary primary care teams. BMC Fam Pract. 2011;12(1):14-23.

52. Kotecha J, Brown JB, Han H, Harris SB, Green M, Russell G, et al. Influence of a quality improvement learning collaborative program on team functioning in primary healthcare. Fam Syst Health: J Collab Family HealthCare. 2015;33(3):222-30.

53. Bachrach DG, Powell BC, Collins BJ, Richey RG. Effects of task interdependence on the relationship between helping behavior and group performance. J Appl Psychol. 2006;91(6):1396-405.

54. Bang H, Park JG. The double-edged sword of task conflict: Its impact on team performance. Soc Behav Personal Int J. 2015;43(5):715-28.

55. Bradley BH, Klotz AC, Postlethwaite BE, Brown KG. Ready to rumble: how team personality composition and task conflict interact to improve performance. J Appl Psychol. 2013;98(2):385-92.

56. Jackson JW. Intragroup cooperation as a function of group performance and group identity. Group Dyn. 2011;15(4):343-56.

57. Jehn KA, Wit FRCD, Barreto M, Rink F. Task conflict asymmetries: effects on expectations and performance. Int J Confl Manag. 2015;26(2):172-91.

58. Reimer T. Attributions for poor group performance as a predictor of perspective-taking and subsequent group achievement: a process model. Group Process Intergroup Relat. 2001;4(1):31.

59. Shaukat R, Yousaf A, Sanders K. Examining the linkages between relationship conflict, performance and turnover intentions. Int J Confl Manag. 2017;28(1):4-23.

60. Verma JP, Modak P, Bhukar JP, Kumar S. A discriminant analysis of team cohesiveness among high-performance and low-performance elite Indian volleyball players. Stud Phys Cult Tour. 2012;19(4):191-5.

61. Warner S, Bowers M, Dixon M. Team dynamics: a social network perspective. J Sport Manag. 2012;26:53-66.

62. You K. Differences in an organization's cultural functions between high and low-performance university soccer teams. SportMont. 2021;18(3):82-8.

63. Butchibabu A, Sparano-Huiban C, Sonenberg L, Shah J. Implicit coordination strategies for effective team communication. Hum Factors. 2016;58(4):595-610

64. Aaberg Cpt W, Thompson CJ, West HV, Swiergosz MJ. Performance improvement: applying a human performance model to organizational processes in a military training environment. Perform Improv. 2009:48(5):16-24.

65. Arnold R, Fletcher D, Daniels K. Demographic differences in sport performers' experiences of organizational stressors. Scand J Med Sci Sports. 2016;26(3):348-58.

66. Arthur W Jr, Glaze RM, Bhupatkar A, Villado AJ, Bennett W Jr, Rowe LJ. Team task analysis: differentiating between tasks using team relatedness and team workflow as metrics of team task interdependence. Hum Factors. 2012;54(2):277-95.

67. Bakker AB, Van Emmerik H, Van Riet P. How job demands, resources, and burnout predict objective performance: a constructive replication. Anxiety Stress Coping. 2008;21(3):309-24.

68. Brodbeck F, Greitemeyer T. A dynamic model of group performance: considering the group members' capacity to learn. Group Process Intergroup Relat. 2000;3(2):159.

69. Buran M, Alexander J, Roddam H, Leather M, Rhodes D. An exploratory study in to the development of a multidisciplinary team in elite level cricket: a thematic analysis. J Res Sports Med. 2019;4(2):1-10.

70. Carmichael F, Thomas D. Team performance: the case of English premiership football. Manag Decis Econ. 2000;21(1):31-45.

71. Firth BM, Hollenbeck JR, Miles JE, Ilgen DR, Barnes CM. Same page, different books: extending representational gaps theory to enhance performance in multiteam systems. Acad Manag J. 2015;58(3):813-35.

72. Hirst G, van Knippenberg D, Zhou Q, Zhu CJ, Tsai PC-F. Exploitation and exploration climates' influence on performance and creativity: diminishing returns as function of self-efficacy. J Manag. 2018:44(3):870-91.

73. Kong DT, Konczak LJ, Bottom WP. Team performance as a joint function of team member satisfaction and agreeableness. Small Group Res. 2015;46(2):160-78.

74. Kurtulus FANA. What types of diversity benefit workers? Empirical evidence on the effects of co-worker dissimilarity on the performance of employees. Ind Relat. 2011;50(4):678-712.

75. Leo FM, Sánchez-Miguel PA, Sánchez-Oliva D, Amado D, García-Calvo T. Analysis of cohesion and collective efficacy profiles for the performance of soccer players. J Hum Kinet. 2013;39:221-9.

76. Lewis K. Knowledge and performance in knowledge-worker teams: a longitudinal study of transactive memory systems. Manage Sci. 2004:50(11):1519-33.

77. Mell JN, Knippenberg DV, Van Ginkel WP. The catalyst effect: the impact of transactive memory system structure on team performance. Acad Manag J. 2014;57(4):1154-73.

78. Sánchez JM, Castellanos P, Dopico JA. The winning production function: empirical evidence from Spanish basketball. Eur Sport Manag Q. 2007;7(3):283-300.

79. Song $\mathrm{JH}$. The key to organizational performance improvement: a perspective of organizational knowledge creation. Perform Improv Q. 2008:21(2):87-102.

80. Sousa Pinto AL, Lourenço PR. The work team's internal functioning: bidimensionality, interdependence and performance. O Funcionamento Interno das Equipes de Trabalho: Bidimensionalidade, Interdependência e Performance. 2014;14(1):3-21.

81. Wright MC, Kaber DB. Effects of automation of information-processing functions on teamwork. Hum Factors. 2005;47(1):50-66.

82. Marques-Quinteiro P, Dos Santos C, Costa P, Graca A, Maroco J, Rico R. Team adaptability and task cohesion as resources to the non-linear dynamics of workload and sickness absenteesim in firefighter teams. Eur J Work Organ Psychol. 2020;29(4):525-40.

83. Bunderson JS, Sutcliffe KM. Comparing alternative conceptualizations of functional diversity in management teams: process and performance effects. Acad Manag J. 2002:45(5):875-93.

84. Lemieux-Charles L, McGuire WL. What do we know about health care team effectiveness? A review of the literature. Med Care Res Rev. 2006;63(3):263-300

85. Ackoff RL. Systems thinking and thinking systems. Syst Dyn Rev. 1994;10(2-3):175-88.

86. Ekstrand J, Lundqvist D, Lagerbäck L, Vouillamoz M, Papadimitiou N, Karlsson J. Is there a correlation between coaches' leadership styles and injuries in elite football teams? A study of 36 elite teams in 17 countries. Br J Sports Med. 2018;52(8):527.

87. Price MS, Weiss MR. Relationships among coach leadership, peer leadership, and adolescent athletes' psychosocial and team outcomes: a test of transformational leadership theory. J Appl Sport Psychol. 2013;25(2):265-79.

88. Rowold J. Transformational and transactional leadership in martial arts. J Appl Sport Psychol. 2006;18(4):312-25.

89. Soane E, Butler C, Stanton E. Followers' personality, transformational leadership and performance. Sport Bus Manag: Int J. 2015;5(1):65-78. 
90. Stenling A, Tafvelin S. Transformational Leadership and Well-Being in Sports: The Mediating Role of Need Satisfaction. J Appl Sport Psychol. 2014;26(2):182-96.

91. Ekstrand J, Lundqvist D, Davison M, D'Hooghe M, Pensgaard AM. Communication quality between the medical team and the head coach/ manager is associated with injury burden and player availability in elite football clubs. Br J Sports Med. 2019;53(5):304-8.

92. Mullins LJ. Essentials of organisational behaviour. London: Pearson Education; 2008.

93. Lausic D, Tennebaum G, Eccles D, Jeong A, Johnson T. Intrateam communication and performance in doubles tennis. Res Q Exerc Sport. 2009;80(2):281-90.

94. Rapley T. Distributed decision making: the anatomy of decisions-inaction. Sociol Health IIIn. 2008;30(3):429-44.

95. Belschak FD, Den Hartog DN. Consequences of positive and negative feedback: the impact on emotions and extra-role behaviors. Appl Psychol: Int Rev. 2009;58(2):274-303.

96. Cole J, Martin AJ. Developing a winning sport team culture: organizational culture in theory and practice. Sport Soc. 2018;21(8):1204-22.

97. Schroeder PJ. Changing team culture: the perspectives of ten successful head coaches. J Sport Behav. 2010;33(1):63-88.

98. Breitbach AP, Reeves S, Fletcher SN. Health care as a team sport?studying athletics to improve interprofessional collaboration. Sports. 2017:5(3):62.

99. Callow N, Smith MJ, Hardy L, Arthur CA, Hardy J. Measurement of transformational leadership and its relationship with team cohesion and performance level. J Appl Sport Psychol. 2009;21(4):395-412.

100. Tekleab AG, Quigley NR, Tesluk PE. A longitudinal study of team conflict, conflict management, cohesion, and team effectiveness. Group Org Manag. 2009;34(2):170-205.

101. Greer LL, Caruso HM, Jehn KA. The bigger they are, the harder they fall: linking team power, team conflict, and performance. Organ Behav Hum Decis Process. 2011;116(1):116-28.

102. Cook CJ, Crewther BT. The social environment during a post-match video presentation affects the hormonal responses and playing performance in professional male athletes. Physiol Behav. 2014;10(130):170-5.

103. Gaviglio CM, Crewther BT, Kilduff LP, Stokes KA, Cook CJ. Relationship between pregame concentrations of free testosterone and outcome in rugby union. Int J Sports Physiol Perform. 2014;9(2):324-31.

104. Serpell BG, Strahorn J, Colomer C, McKune A, Cook C, Pumpa K. The effect of speed, power and strength training, and a group motivational presentation on physiological markers of athlete readiness: a case study in professional Rugby. Int J Sports Physiol Perform. 2018;12:1-15.

\section{Publisher's Note}

Springer Nature remains neutral with regard to jurisdictional claims in published maps and institutional affiliations.

\section{Submit your manuscript to a SpringerOpen ${ }^{\circ}$ journal and benefit from:}

- Convenient online submission

- Rigorous peer review

- Open access: articles freely available online

- High visibility within the field

- Retaining the copyright to your article 